\title{
Moda, Cultura \& Frascos de Perfume
}

\author{
Fashion, Culture and Perfume Bottles
}

FRANÇA, Maureen Schaefer; Mestre; UTFPR

maureen.schaefer@gmail.com

QUELUZ, Marilda Lopes Pinheiro; Doutora; UTFPR

pqueluz@gmail.com

\begin{abstract}
Resumo
Os estudos apresentados neste artigo buscam refletir sobre a relação entre design e cultura presente nos frascos de perfume do século XXI. O objetivo é compreender algumas representações sociais construídas através do design de frascos de perfume após o seu encontro com a moda e as suas relações com a criação de espaços de identificação para os consumidores potenciais. Procurouse estudar os envoltórios em sua materialidade, o modo como constituem e são constituídos por discursos sócio-culturais, questionando ou reproduzindo estereótipos, convenções sociais e relações de poder. Para isso, recorreu-se à análise da configuração visual, mediada pelas questões sócioculturais, de duas embalagens de perfume: $\mathrm{CH}$ e CH Men, ambas da estilista Carolina Herrera, voltadas, respectivamente, para o público feminino e masculino. As embalagens costumam dar visibilidade a tipos de feminilidades e masculinidades e estilos de vida, que são atravessados por questões de gênero, geracionais e classistas. Os frascos de perfume, assim como outros produtos do design, permitem observar parte da representação da sociedade contemporânea.
\end{abstract}

Palavras-Chave: Design e cultura; Frasco de perfume; Design de embalagem.

\begin{abstract}
The studies presented in this article seek reflections on the relationship between design and culture present in the bottles of perfume of the XXI century. The goal is to understand some social representations constructed through the design of perfume bottles after his meeting with fashion and its relationship with the creation of spaces for the identification of potential consumers. Tried to study the packages on its materiality, how they constituted and are constituted by socio-cultural speeches, questioning or reproducing stereotypes, social conventions and power relations. To this end, we resorted to the analysis of visual configuration, mediated by socio-cultural issues, of two packages of perfume: Men $\mathrm{CH}$ and $\mathrm{CH}$, both the designer Carolina Herrera, directed, respectively, for female and male. The packages usually give visibility to types of femininities and masculinities and lifestyles, which are divided by gender, generational and class. Perfume bottles, as well as other products of design, allow people to observe part of the representation of contemporary society.
\end{abstract}

Keywords: Design and culture; Perfume bottle; Package design.

\section{Design, cultura e frascos de perfume}

É possível que para algumas pessoas a alteração da configuração dos artefatos esteja ligada a algum tipo de evolucionismo tecnológico. Isto não quer dizer que as inovações tecnológicas não influenciem o design de produtos, contudo, este tipo de pensamento parece apagar a importância das relações sócio-culturais, políticas e econômicas no desenho de 
artefatos.

O design de produtos não é uma atividade neutra, pois a escolha de conceitos, elementos formais e processos produtivos é mediada pelo contexto cultural no qual o designer está inserido. A cultura funciona como uma lente através da qual o indivíduo percebe o mundo (BENEDICT apud LARAIA, 2007), influenciando seus pensamentos, ações e produções.

$O$ design de artefatos é influenciado por questões sócio-culturais como também pelas questões políticas, econômicas e inovações tecnológicas de determinado contexto. Para Winner (1999), os produtos são políticos, podendo ser desenhados, conscientemente ou não, para abrir ou fechar certas opções sociais.

Os artefatos e sistemas tangíveis e intangíveis também influenciam a sociedade, afetando a construção de seus hábitos e valores, seu desenvolvimento físico e psíquico assim como suas atividades e relações sociais (ONO, 2004).

Portanto, o design de produtos tem função formativa dentro da sociedade e da cultura, pois através do seu uso, da sua configuração e dos significados que pode evocar, é capaz de comunicar mensagens complexas, que podem ser aceitas ou transformadas dentro do contexto de consumo, mas dificilmente ignoradas. Neste sentido, o design é visto como parte do processo dinâmico através do qual a cultura e a sociedade são construídas, e não apenas seu reflexo (SPARKE, 2004).

\section{Século XVIII e XIX: transformações plásticas e culturais dos frascos e dos perfumes}

A configuração dos envoltórios de perfume mudou muito ao longo dos séculos, refletindo questões tecnológicas, econômicas e sócio-culturais. No século XVIII, por exemplo, o fenômeno cultural Kitsch influenciou a criação de diversos envoltórios figurativos com temáticas deslocadas do contexto original. As garrafas mais lembravam bibelôs, brinquedos ou peças decorativas com apelo emocional; uma transformação que se reflete ainda hoje no design de frascos de perfume (FRANÇA, 2011).

No século XIX, a compra de perfumes acontecia de forma bastante personalizada: o cliente escolhia não apenas a fragrância, mas também a embalagem. Este evento acabou por incentivar a produção de uma vasta gama de envoltórios, a fim de agradar o gosto pessoal do consumidor (ASHCAR, 2001).

Mas os perfumes ainda compartilhavam frascos genéricos com outros fragrantes, diferenciando-se apenas pelos rótulos. O cenário só mudou com o surgimento das lojas de departamento, com o crescimento do mercado global e da concorrência entre os fabricantes, que acabaram por incentivar a criação de um nome, de um frasco e de uma caixa específicos para cada perfume (CORNING MUSEUM OF GLASS, 2010).

Já no final do século XIX, os perfumes passaram a ser criados e comercializados de acordo com duas categorias: famílias olfativas femininas e masculinas. Fougère Royale (fig. 1), de 1882, criado pela Houbigant, é o fragrante mais antigo de que se tem notícia a ser lançado exclusivamente para o público masculino (ASHCAR, 2010). 


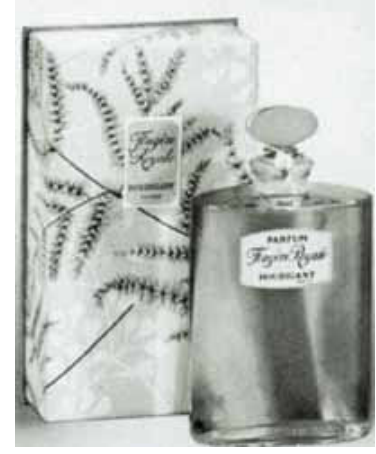

Figura 1- Frasco do perfume Fougère Royale Fonte: PERFUME 2000.COM (2010)

Este evento acabou por lançar algumas convenções de uso para as fragrâncias, que se refletem ainda hoje: os tipos floral, doce e frutal para as mulheres e os tipos fougère e conífero para homens, por exemplo (ASHCAR, 2001).

Os fragrantes fougère lembram o cheiro da relva, sendo compostos por notas de musgo de carvalho, lavanda e cumarina. Segundo Ashcar (2001), o fragrante Fougère Royale, que batizou o conceito fougère, fascinou os nobres cavalheiros parisienses do final do século XIX, por associar-se às sensações olfativas das atividades de caça, culturalmente vistas como práticas masculinas, organizadas pela realeza francesa em bosques banhados de orvalho.

Já os perfumes feitos com notas florais, geralmente destinados ao público feminino, parecem estar associados historicamente a alguns conceitos culturais das flores: sensibilidade, delicadeza, fragilidade e fertilidade (FRANÇA, 2011).

Segundo Knibiehler (1991), tudo aquilo que traduzia ideias de sensibilidade, pureza e delicadeza das mulheres era bastante valorizado na Europa do século XIX: o uso de laços e fitas, cabelos encaracolados e pele clara. Logo, é possível que os perfumes florais também fizessem parte do sistema desse discurso sócio-cultural.

É interessante notar que desde então, apesar de não se conhecer uma data precisa, o design de frascos de perfume tem materializado conceitos que costumam estar associados às mulheres e aos homens. Neste sentido, pode-se dizer que o gênero, compreendido como um conjunto de discursos e práticas que constroem e reformulam limites para os sexos (SANTOS, 2010), acaba por balizar o processo de criação e o consumo dos frascos e dos perfumes.

É possível notar, por exemplo, que muitos frascos destinados às mulheres compartilham cores, formas, tipografias e materiais similares que são diferentes daqueles empregados nas embalagens direcionadas ao público masculino. Isto se deve, provavelmente, aos significados gendrados que são atribuídos culturalmente a tais elementos plásticos. Contudo, é importante ressaltar que tais significados não são inerentes aos artefatos e nem permanentes, variando de acordo com o contexto local e temporal.

\section{Século XX e XXI: a conexão entre moda e perfumaria}

A garrafa em si se associou cada vez mais ao conteúdo, no início do século XX, em grande parte devido ao trabalho conjunto de uma dupla francesa: o perfumista Coty e o designer René Lalique. A busca de Coty e de Lalique por envoltórios da mais alta qualidade para venda comercial revolucionou as ideias sobre o design de frascos de perfume, transformando-os em verdadeiras jóias de museus (PERFUMES: a história..., 2010). 
A apresentação visual dos perfumes cresceu em importância, tornando-se uma arte de embalar sonhos e desejos. Christie Mayer Lefkowith, expert em frascos de perfume antigos, considera a virada do século XX o apogeu do luxo engarrafado, quando o rótulo tradicional em garrafa anônima deixou de ser suficiente para seduzir o consumidor (MESTRINER, 2002).

A preocupação com a criação de frascos de perfume tornou-se cada vez maior, tanto que artistas de prestígio passaram a ser contratados para configurá-los. É o caso de Salvador Dalí (1904-1989), que desenhou o frasco do perfume Le Roi Soleil (fig. 2) para a estilista Elsa Schiaparelli, em 1946, e Fernand Léger (1881-1955), pintor francês, que projetou o vidro de Cantillène para Reveillon (OLIVEIRA, 2006).

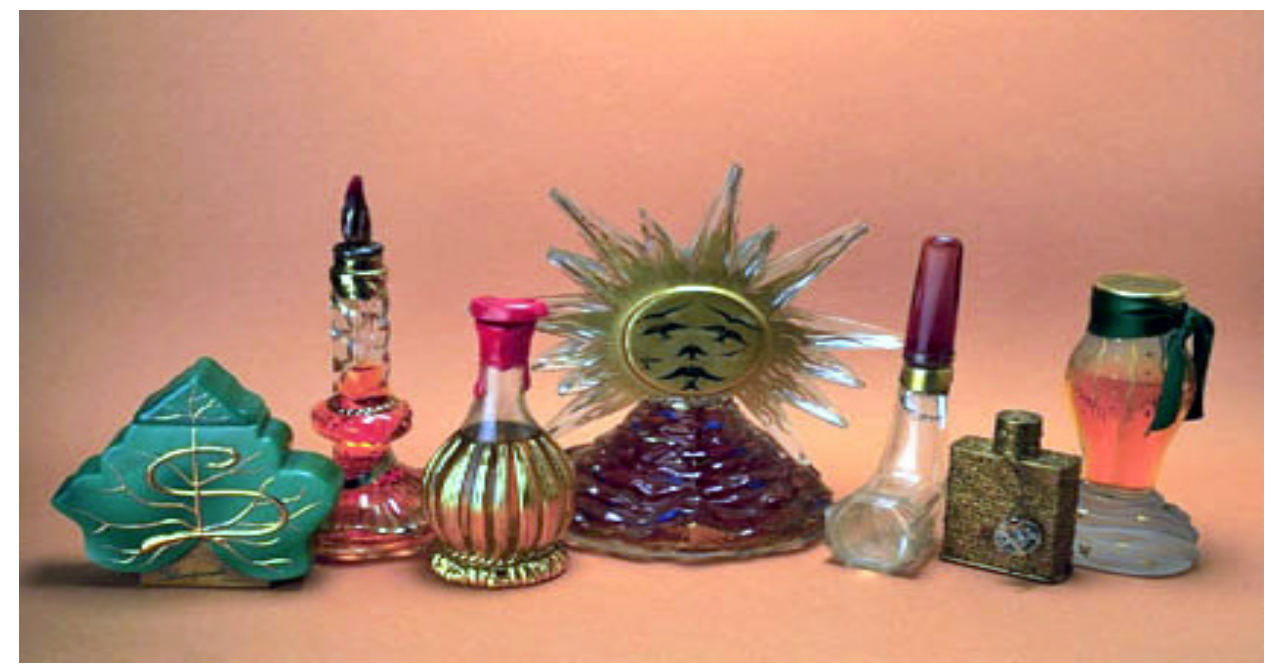

Figura 2- Perfumes da estilista Elza Schiaparelli.

Fonte: Buera (2009).

Obs: Da esquerda para direita - Succes Fou (1953), SI (1957), Sleeping (1938), Le Roi Soleil (1946), Snuff (1940), Zut (1949) e Shocking (1936).

Os fragrantes ganharam novos olhares na primeira década do século $\mathrm{XX}$, quando a perfumaria conectou-se à moda. A aparição das "fragrâncias de estilistas", primeiramente com Poiret (1879-1943), em 1912, tornou a relação entre moda e perfumaria mais visível, alterando a percepção e a concepção de frascos e fragrantes (ASHCAR, 2001).

"A tendência lançada por Poiret antes da I Guerra Mundial expandiu-se rapidamente. Depois de Chanel, cada nome da alta-costura assinava pelo menos uma fragrância: Patou, Molyneux, Worth, Schiaparelli, Weil" (ASHCAR, 2001, p. 150).

A apresentação visual do perfume composta pela garrafa, rótulo e caixa e a sua publicidade destinavam-se a vender uma imagem e não apenas uma fragrância (CORNING MUSEUM OF GLASS, 2010).

Os fragrantes tornaram-se parte da moda, emprestando mecanismos do seu sistema. Junto ao vestuário, os envoltórios, os perfumes e seus sistemas discursivos passaram a delinear padrões de comportamento, perfis e estilos de vida (FRANÇA, 2011).

Apesar dos perfumes terem sido utilizados durante muito tempo como artigos de higiene, eles parecem funcionar hoje como um acessório, como o toque final de uma produção, associando-se a termos usados no mundo da moda: eles podem ser elegantes, clássicos, sofisticados, esportivos, glamourosos ou modernos.

O design do frasco do perfume Chanel no 5 (fig. 3), de 1921, por exemplo, apostava

Projética Revista Científica de Design I Universidade Estadual de Londrina I V.2 I N.2 I Dezembro 2011 
Moda, Cultura \& Frascos de Perfume

na geometrização. Escolhido pela estilista Chanel (1883-1971), a garrafa representou uma ruptura com as linhas românticas prevalecentes da época, conquistando consumidoras com sua estética retilínea, que revelava certa modernidade e sobriedade (CHANEL, 2010).

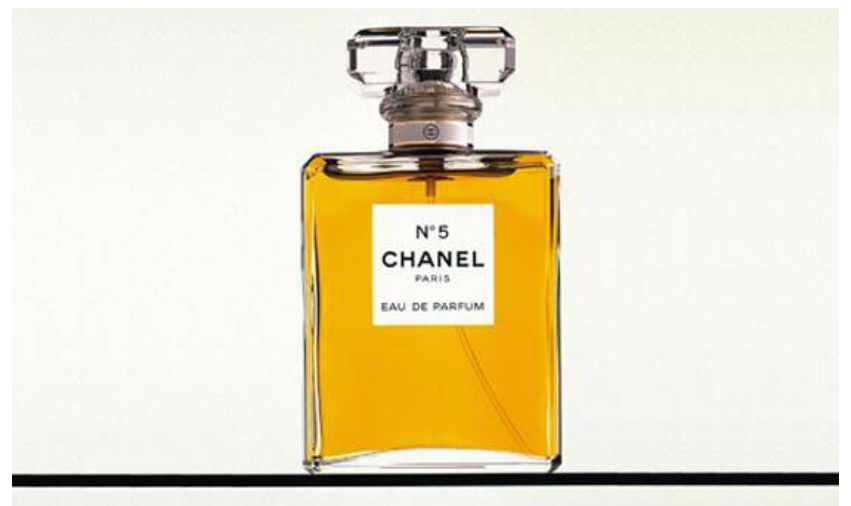

Figura 3- Frasco do perfume Chanel $n^{\circ} 5$.

Fonte: CHANEL (2010)

O fragrante Chanel $\mathrm{N}^{\circ} 5$, que se tornou um dos grandes ícones da perfumaria do século XX, fez parte dos planos da estilista de aliar as fragrâncias à maneira de viver do público. Chanel buscava vender não apenas novas silhuetas e fragrâncias aos consumidores, mas antes disso, um estilo de vida permeado por suas criações (ASHCAR, 2001).

Já os sabonetes, entre outros produtos que foram usados como perfumes, recebem uma classificação à parte dos fragrantes, propagando significados diferentes, aliados às questões práticas de higiene: eles prometem deixar a pele macia, sedosa e com brilho.

Há alguns casos em que o design de frascos de perfume acaba por emprestar silhuetas e modelagens lançadas pela indústria do vestuário. Na década de 1950, o New Look de Christian Dior (1905-1957) tornou-se uma das principais referências da moda, procurando resgatar um tipo de feminilidade que, para alguns, havia sido deixada de lado durante os anos de guerra (SEELING, 2000).

As formas do New Look chegaram a se manifestar na arquitetura, na decoração de interiores, no mobiliário de formas orgânicas, nos copos em forma de tulipa (SEELING, 2000) e até mesmo em frascos de perfume.

O corpo da embalagem do primeiro perfume norte-americano de sucesso, Youth Dew (fig. 4), por exemplo, sugere uma alusão à cintura marcada do New Look e a um tipo de feminilidade convencional atribuído a ele.

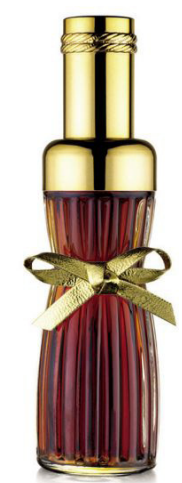

Figura 4- Frasco do fragrante Youth Dew de 1952, de Estée Lauder

Fonte: Estée Lauder (2010) 
As ocasiões de uso dos perfumes também demonstram estar relacionadas à moda. As mídias sobre perfumes, especialmente as revistas de moda do início do século XXI, costumam trazer discursos sobre as ocasiões de uso dos fragrantes. Elas têm construído a ideia de que os perfumes, assim como as peças de moda, podem combinar com os compromissos do dia a dia. Eles podem variar de acordo com a hora do dia e a estação do ano e segundo as atividades sociais do sujeito e os lugares frequentados (FRANÇA, 2011).

O uso noturno e/ou diurno dos fragrantes está associado, em alguns casos, à intensidade e ao efeito do perfume. Costuma-se dizer que os aromas mais marcantes devem ser reservados para noite e momentos mais especiais enquanto os mais leves e refrescantes são direcionados para o dia e ocasiões mais casuais.

A configuração dos frascos pode dar visibilidade ao uso noturno ou diurno através de cores mais sóbrias ou leves e acabamentos incolores ou opacos, embora este repertório visual não funcione como uma regra fixa.

O conceito de ocasião de uso do perfume também sugere locais de utilização para o fragrante. Cria-se a ideia de que ele pode ser usado na praia, na academia e na "balada", por exemplo (Quadro 1).

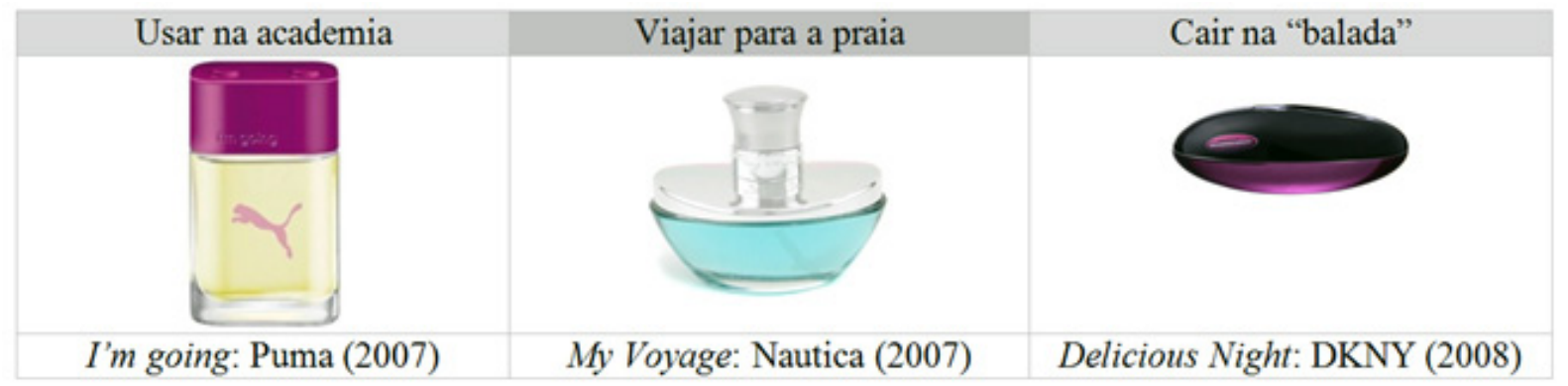

Quadro 1- Perfumes para usar na academia, na praia e na "balada".

Fonte: Bellino (2009).

É possível que esta construção do local de uso dos aromas esteja ligada não apenas às cores e ao nome do fragrante como em Delicious Night, mas também às formas da embalagem, como ocorre na garrafa de My Voyage, que tem formato semelhante ao de um barco.

Ainda é possível que a sugestão do local de uso remeta à marca do fragrante, como no caso do perfume I'm going, sugerido para se usar na academia, lembrando a marca Puma, empresa de roupas e acessórios esportivos.

Os locais sugeridos e as práticas e atividades que costumam estar associadas aos perfumes podem aparecer ainda como indicadores de estilos de vida imaginados, criando espaços de identificação para os usuários potenciais.

Estas sugestões e classificações são parte da estratégia dos produtores de lançar perfumes para nichos de mercados especializados, ampliando a margem de persuasão e negociação com a grande diversidade de consumidores. Se estas construções simbólicas forem legitimadas, elas são capazes de transformar a percepção social do frasco e do perfume e dos seus hábitos de uso.

\section{Frascos de perfume: pontos de ancoragem}

O consumo de artigos funciona como prática e comunicação da distinção simbólica e 
Moda, Cultura \& Frascos de Perfume

social. Para Slater (2002), o consumo é uma questão de como os sujeitos sociais relacionam-se com as coisas do mundo (bens, serviços, experiências materiais e simbólicas). O consumo vai muito além do ato da compra, abrangendo não somente os usos dos artefatos no dia-a-dia, mas também suas reinterpretações, modificações e transgressões.

Os usos de objetos, mediados pelo poderio socioeconômico, podem indicar a participação, ascensão ou exclusão de um indivíduo de um grupo social, servindo como um aspecto de diferenciação e identificação.

De acordo com Miller (2009), o consumo das coisas faz parte da construção das pessoas e da percepção do "eu", sendo capaz de influenciar a identidade e o comportamento dos sujeitos, alterando seus pensamentos e modos de agir. Muito do que faz das pessoas serem aquilo que são ou buscam ser, existe na materialidade externa a seu corpo.

O sujeito constrói suas identidades e subjetividades através, mas não somente, de produtos, ancorando-se nas imagens e nos significados simbólicos que os objetos projetam. Pois segundo Medeiros e Queluz (2008), todo e qualquer artefato produz e está associado a uma identidade, tanto tecnicamente quanto culturalmente, para atingir os consumidores que irão comprar e usar este produto, que supostamente os identificarão para sociedade.

A roupa é um dos principais meios de externar uma narrativa particular do "eu". Após a conexão entre perfume e moda, a indústria da perfumaria parece investir cada vez mais na ideia de que os fragrantes agem como uma roupa invisível, que seria capaz de refletir a personalidade e o estilo de vida do usuário.

As embalagens representam os conceitos do perfume e, assim como outras mídias discursivas, interpelam os sujeitos sociais a assumirem esses significados, investindo suas emoções neles para construírem a si mesmos (HALL, 1997). Pois, as identidades são "pontos de apego temporário às posições-de-sujeito que as práticas discursivas constroem para nós" (HALL, 2000, p. 112).

Os frascos de perfume não refletem identidades previamente existentes, mas mediando as relações sociais, servem como pontos de apoio para que as pessoas (re)construam constantemente suas subjetividades e identidades.

Os frascos de perfume são representações, ou seja, interpretações de algum referente materializadas através da linguagem, um sistema sócio-cultural de codificação das ideias sobre o mundo, capaz de compartilhar significados (HALL, 1997).

Vale lembrar que "o significado de qualquer objeto reside não no objeto em si, mas é produto da forma como esse objeto é socialmente construído através da linguagem e da representação" (DU GAY, 1994 apud HALL, 1997, p. 28).

Os envoltórios de perfume são sistemas simbólicos de representação capazes de evocar significados culturais que têm efeitos reais nas pessoas, regulando práticas sociais e assinalando diferenças. São artefatos que "delimitam espaços, estabelecem fronteiras por meio das quais são marcadas as diferenças em relação a outras possibilidades de identificação" (SANTOS, 2008, p. 40).

Algumas embalagens de perfume direcionadas para o público infantil, por exemplo, costumam apresentar elementos táteis e visuais diferentes daqueles voltados para o público adulto. Há muitos exemplares de embalagens infantis que trazem motivos inspirados em animais, que são antropomorfizados para evocar ideias de doçura e fofura a fim de que as crianças criem empatia por eles (FRANÇA, 2011).

Seguindo o pensamento de Forty (2007), pode-se dizer que a aparência de frascos infantis inspirados em animais dialoga com as crenças de que as crianças são ingênuas, inocentes e brincalhonas. Esta relação possível entre os significados e o significante poderia causar certa estranheza caso o envoltório fosse direcionado para o público adulto.

Projética Revista Científica de Design I Universidade Estadual de Londrina I V.2 I N.2 I Dezembro 2011 
A partir dos anos 1970, de acordo com Ono (2006), verificou-se a busca de uma maior diversificação de produtos. Na indústria da perfumaria, a grande variedade de perfumes e de embalagens nas últimas décadas pode estar associada não apenas ao barateamento dos processos produtivos e ao objetivo de gerar riqueza, mas também à preocupação em atender às necessidades dos consumidores de expressar seu sentimento de individualidade.

A diversificação e a segmentação do mercado fazem parte da estratégia de identificação entre os consumidores e os produtos, sendo atravessada por questões de classe, de gênero e geração, que reforçam as distinções dentro da sociedade, acompanhando suas transformações. As organizações produtivas passaram a se preocupar não apenas com as diferenciações de gênero, mas também "com os diferentes perfis de consumidores, com a diversidade cultural e hábitos de consumo" (ONO, 2006, p. 76).

De acordo com Forty (2007), a grande variedade de artigos visa atender não somente às muitas categorias diferentes de usuário, mas à grande variedade existente dentro de cada categoria.

Nesta perspectiva, a indústria da perfumaria costuma apoiar-se ainda em outros discursos, sugerindo consumidores potenciais/imaginados com perfis e estilos de vida préestabelecidos para os produtos, uma estratégia que parece ter ligação histórica com a tentativa da estilista Chanel de aliar os fragrantes aos estilos de vida.

\section{Frascos de Perfume \& Usuários imaginados}

De acordo com Filomena Padron, designer da Natura Cosméticos, é complicado criar a mesma embalagem para vários perfumes, pois cada um tem a sua personalidade e é preciso traduzi-la (ARTE em perfumes... 2010).

A construção da personalidade dos perfumes diz respeito, às vezes, à ideia de humanizar seus atributos, como no caso em que o Guia de Perfumes (2010) sugere que os perfumes podem ser envolventes, sedutores, enigmáticos, cativantes. A personalidade dos perfumes ganha contornos através dos discursos das mídias dos fragrantes: propagandas, revistas de moda, websites e embalagens. Muitas vezes, as mídias criam representações que parecem incorporar a personalidade dos fragrantes: os usuários imaginados.

Os usuários imaginados para os perfumes seriam esse espaço possível de identificação para o consumidor. Eles se referem à invenção de tipos de mulheres e de homens que supostamente usam ou combinam com determinados perfumes.

A construção dos usuários imaginados é permeada por valores culturais, sugerindo estilos de vida, tipos de feminilidades e masculinidades, cortes geracionais e classistas, por exemplo. Entretanto, estes usuários imaginados dificilmente existem na realidade, pois não se tratam de pessoas reais de carne e osso, mas de usuários fictícios (FRANÇA, 2011).

As mídias utilizam diversos recursos discursivos para representar os usuários imaginados. Os Guias de Perfumes, alguns sites e revistas de moda e comportamento, por exemplo, trazem testes de personalidade a partir dos quais os consumidores são classificados em algum perfil pré-estabelecido (sedutor, esportivo, moderno, clássico, romântico, sofisticado e etc.), que supostamente, combina com determinados tipos de perfume.

As propagandas impressas e televisivas tornam o usuário imaginado visível. Elas abrangem modelos que são capazes de incorporar maneiras de se vestir e de se portar, que supostamente, correspondem as dos usuários imaginados. As propagandas podem englobar os artefatos que fazem parte do universo do consumidor fictício como também suas ações e 
Moda, Cultura \& Frascos de Perfume

preferências: se eles gostam de viajar e dançar; se eles preferem a simplicidade ao luxo ou rock à música eletrônica, por exemplo.

Neste sentido, as propagandas de perfume podem ser consideradas mídias de estilos de vida , pois segundo Santos (2010), estas mídias favorecem a circulação de valores que afetam a constituição, reformulação ou rompimento das identificações individuais e coletivas no interior da cultura de consumo, sendo capazes de delinear as diferenças sociais.

$O$ design de embalagens também é capaz de materializar o usuário imaginado para determinado perfume. Utiliza para isso, cores, formas, materiais, tipografias e texturas, que, em conjunto, podem evocar ou eliminar certos significados para o leitor, segundo seu sistema de referências sócio-culturais individuais e coletivas.

De acordo com a perspectiva de Oliveira (2006), as pessoas são capazes de se encontrar nos discursos sobre as fragrâncias, já que eles podem dizer respeito aos atributos que os sujeitos sociais possuem, pensam que possuem ou gostariam de possuir.

Os discursos em torno dos fragrantes formam um conjunto de pontos de apego para o consumidor. Entretanto, o usuário pode se identificar apenas com alguma referência simbólica do perfume e não com todo o conjunto discursivo.

\section{Análise da configuração plástica de frascos de perfume mediada por questões culturais}

Neste tópico, procura-se analisar a relação entre cultura e frascos de perfume com maior profundidade. Busca-se compreender, especialmente através da configuração e da linguagem dos frascos de perfume, a construção de usuários imaginados para os fragrantes. Os produtos são construídos a partir de linguagens verbais e não-verbais, através das quais certos significados podem ser reconhecidos ou não. A cultura atua como um complexo sistema de códigos que orienta a leitura dos objetos do cotidiano.

Logo, por mais que a análise seja realizada apenas por uma pessoa, que tem suas próprias experiências, ela não traz apenas leituras unilaterais. Pois a análise é mediada pela cultura na qual o(a) leitor(a) está inserido(a), compartilhando significados, convenções sociais e modos de pensar com outros sujeitos.

As análises aqui propostas não esgotam outras possibilidades de leitura. Elas não negam o caráter polissêmico dos frascos de perfume, nem o processo dialógico de interpretação de significados.

Além disso, de acordo com os pensamentos de Joly (1996), pode-se dizer que a análise não está e nunca ficará presa aos sentidos previstos pelo projeto do frasco de perfume. Os signos tendem a assumir novas características, dependendo de como, onde e por quem são lidos. Uma vez que o artefato é lançado em determinado contexto, ele passa a interagir com a dinâmica das relações culturais, constituídas historicamente.

\section{Amostragem e Metodologia}

Optou-se por analisar dois frascos de perfume do século XXI. Foram escolhidas duas embalagens de perfume de uma estilista, devido a sua ligação mais direta com a moda e consequentemente, com a construção de perfis e estilos de vida imaginados.

Foram selecionadas duas embalagens de perfume da estilista Carolina Herrera: uma 
Lucas J. Garcia; Júlio M. Teixeira; Eugenio A. D. Merino; Leila A. Gontijo

direcionada para o público feminino e outra para o público masculino, são elas: $\mathrm{CH}$ e $\mathrm{CH}$ Men. Foi dada maior atenção à análise das embalagens de perfume, entendidas como um texto tátil e visual, como um objeto estético que produz um discurso. Mas o estudo também considerou as informações divulgadas por outras mídias do perfume, pois estas fazem parte do sistema de referências do produto, podendo servir de auxílio para a leitura dos frascos de perfume.

Deste modo, foram considerados websites, propagandas impressas e televisivas, ampliando o rol de informações sobre os fragrantes, trazendo, em alguns casos, as opiniões dos perfumistas, estilistas e designers sobre os conceitos dos perfumes e das embalagens.

As análises tiveram início com as informações sobre os estilistas selecionados e suas produções a fim de perceber, de modo sucinto, o contexto no qual a embalagem está inserida e a interação entre a linguagem da grife e a proposta do frasco de perfume.

A seguir, foram descritas referências sobre a composição e/ou o conceito do fragrante de modo a fazer associações com a configuração plástica dos perfumes. Depois, deu-se início à leitura da embalagem a partir de Joly (1996), considerando-se os signos plásticos, icônicos e linguísticos e a interpretação de mensagens denotativas e conotativas com o objetivo de delinear os usuários imaginados e demais distinções sociais dos perfumes.

Primeiramente, analisou-se a estrutura do envoltório de perfume que costuma abranger as seguintes partes: tampa, corpo da embalagem, atomizador e acessórios.

Em seguida, foram descritos os elementos plásticos, icônicos e linguísticos que as compõem - cores, materiais, formas, texturas, imagens e tipografias - e a relação entre eles, ou seja, a sua organização.

Durante o processo de leitura, buscou-se perceber possíveis denotações e conotações dos elementos e suas associações com os conceitos do perfume. Entretanto, vale lembrar que os significados elencados durante a análise foram tecidos a partir de referências culturais ocidentais.

E por último, tentou-se delinear o(a) usuário(a) imaginado(a) a partir das ideias que os fragrantes, as embalagens e demais mídias parecem evocar.

\section{CH Carolina Herrera}

Carolina Herrera (1939-), estilista venezuelana radicada em Nova lorque desde 1981, desenvolve roupas para o público feminino e masculino, além de artigos de couro como malas e sapatos, tendo ingressado no setor da perfumaria no final da década de 80, em 1988.

A estilista costuma trabalhar com babados, vestidos com cintura marcada, decotes reservados e comprimento das saias longo ou na altura dos joelhos, produzindo peças elegantes, sofisticadas e de uma sensualidade moderada (fig. 5). O matiz vermelho do logotipo da grife costuma estar presente em diversas coleções da estilista, reforçando a imagem da marca.

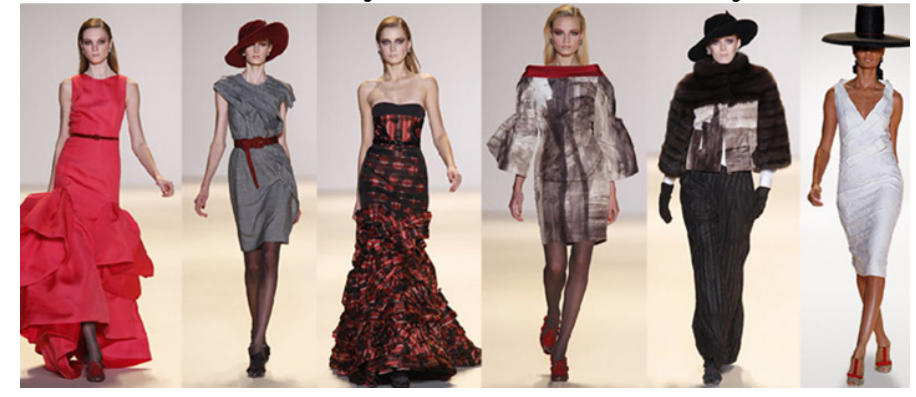

Figura 5- Peças da linha Carolina Herrera New York

Fonte: Carolina Herrera (2010)

Projética Revista Científica de Design I Universidade Estadual de Londrina I V.2 I N.2 I Dezembro 2011 
Moda, Cultura \& Frascos de Perfume

Em 2007, a grife lançou o fragrante CH Carolina Herrera, destinado ao público feminino. O perfume foi desenvolvido por Carolina Jr., filha da estilista, que também direcionou o design da embalagem (GUIA DE PERFUMES, 2010; CAROLINA HERRERA, 2010).

Carolina Jr. resgatou suas memórias olfativas para criar o chipre frutal $\mathrm{CH}$ : a casa da mãe, a sobremesa favorita, os locais onde passava as férias. A autora do fragrante explica o conceito da blenda (GUIA DE PERFUMES, 2009, p. 46):

Na saída, notas frescas e cítricas são as recordações dos verões, o lado mais jovem e divertido. Depois, acordes quentes com a rosa búlgara, o jasmim e o pralinê me remetem a momentos tranquilos e pessoais, que denotam meu amor pela vida familiar. Tudo faz mais sentido ainda graças às notas suaves de couro e caxemira que me levam aos campos da Calábria.

O corpo da embalagem é cilíndrico (fig. 6). As formas arredondadas costumam ser usadas em produtos destinados ao público feminino, representando, culturalmente, ideais de feminilidade convencional, emoção e sensibilidade. O corpo, que é feito de vidro, tem configuração simétrica, apresentando estabilidade, robustez e pouco dinamismo, compondo um visual mais "comportado".

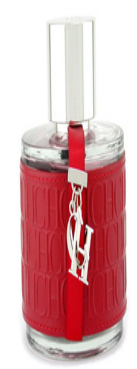

Figura 6- Frasco do perfume $\mathrm{CH}$

Fonte: Carolina Herrera (2010)

A tampa, revestida com metal, também é cilíndrica, trazendo no seu topo uma gravação em baixo relevo composta em duas linhas. Na primeira linha, as letras " $\mathrm{C}$ " e " $\mathrm{H}$ " e na segunda, " $H$ " e "C" (fig. 07) fazem menção ao nome do perfume.

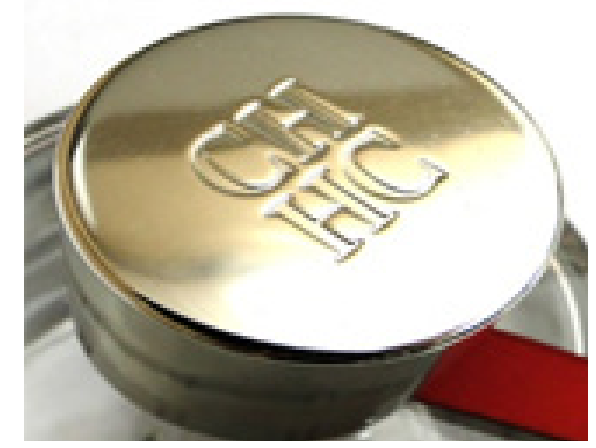

Figura 7- Gravação das letras " $\mathrm{C}$ " $\mathrm{e}$ " $\mathrm{H}$ " na tampa do frasco do perfume $\mathrm{CH}$

Fonte: Elaborado pelas autoras (2010).

A inscrição " $\mathrm{CH}$ e $\mathrm{HC}^{\prime}$ da tampa é idêntico ao módulo de repetição da padronagem do couro avermelhado (fig. 08), que reveste o corpo da embalagem. A padronagem do couro, que é pespontado nas laterais, tem estrutura formal, sendo construída de maneira rígida e 
matemática (WUCIUS, 1998). A estrutura formal pode remeter a algo regular e previsível, como também à ideia de tradição e de vida familiar, reiterando a fonte que inspirou a criação da fragrância.

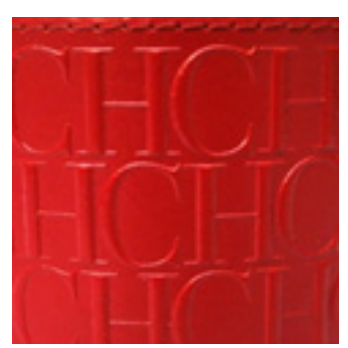

Figura 8- Padronagem em relevo do couro vermelho que recobre a embalagem

Fonte: Elaborado pelas autoras (2010).

O uso do couro pode remeter às peças de couro, que são normalmente caras, podendo significar luxo e riqueza. Ao aliar-se com o vermelho, o couro parece ganhar outros sentidos: paixão, desejo e sedução.

A cor avermelhada e a padronagem do couro aparecem também no figurino da modelo da propaganda do fragrante $\mathrm{CH}$ (fig. 9 e 10). A partir desta associação, o couro parece revestir o corpo de vidro como um espartilho, evitando que ele fique desnudo. Neste sentido, o couro avermelhado parece evocar ainda um tipo de fetiche, algo mais picante e provocativo. Contudo, a padronagem de estrutura formal gravada no couro acabam por atenuar tais associações. A sensualidade da embalagem aparece apenas insinuada.

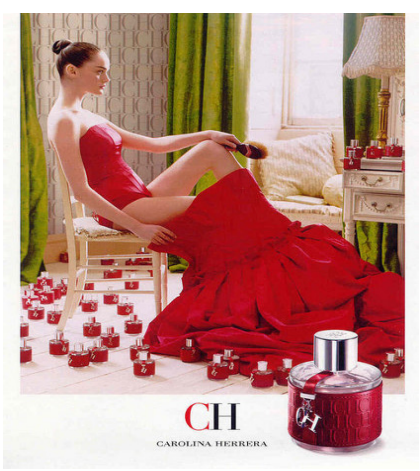

Figura 9- Propaganda impressa do perfume $\mathrm{CH}$ Fonte: Carolina Herrera (2010)

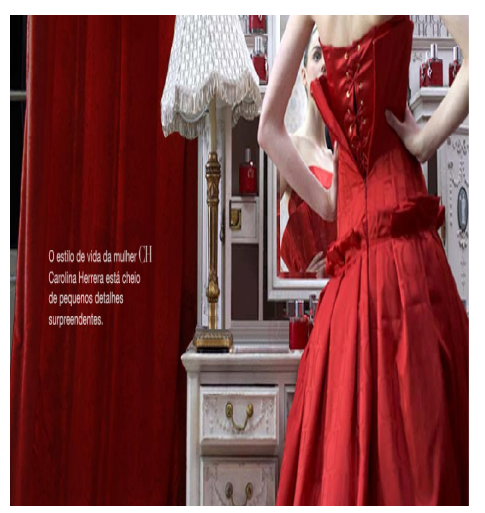

Figura 10- Detalhe do figurino da modelo Fonte: Carolina Herrera (2010) 
Da base do atomizador parte uma fita de cetim vermelha que atravessa a parte superior do corpo da embalagem até cair pela lateral. Nela há dois pingentes - as iniciais de Carolina Herrera (fig. 11). As letras " $\mathrm{C}$ " e " $\mathrm{H}$ ", que se espalham por grande parte do envoltório, são desenhadas em caixa alta e apresentam serifa, podendo fazer referência a algo clássico e elegante.
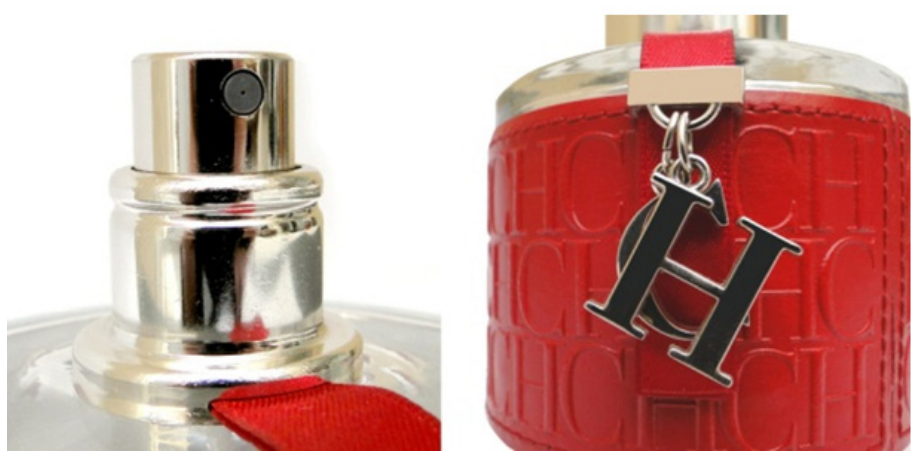

Figura 11- Pump e pingentes do frasco Fonte: Elaborado pela autora (2010).

Os pingentes " $\mathrm{C}$ " e " $\mathrm{H}$ " parecem conferir um tom mais lúdico à embalagem, suavizando sua estrutura formal.

Apesar das associações entre o frasco de perfume e a imagem do figurino da propaganda, segundo o site da grife, a embalagem foi inspirada nas caixas redondas usadas para guardar chapéus (fig. 12). O formato cilíndrico, o couro e o pespontado da embalagem fazem ainda mais sentido.

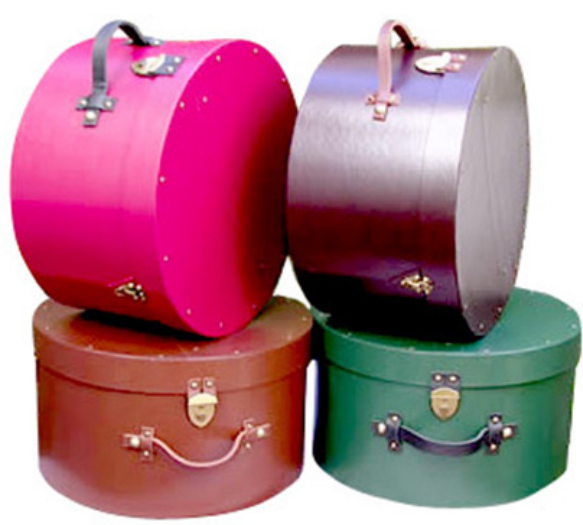

Figura 12- Caixas de couro para guardar chapéus

Fonte: Tania Bo. Cartonagem (2010)

O uso da referência destas caixas acaba por fazer menção também ao conteúdo que estas guardam, ou seja, os chapéus, uma das peças criadas pela estilista Carolina Herrera. Segundo Sevcenko (1998), na Belle Époque, o chapéu feminino era objeto de desejo das damas e manifestavam códigos sociais complicadíssimos.

Naquela época, os chapéus variavam conforme a idade, estado civil, condição social, posição do pai ou marido, estação, ambiente, hora do dia, características dos vestidos e joias em uso, as modas das companhias teatrais parisienses e os últimos lançamentos das butiques francesas. 
O chapéu era símbolo de uma ideia de feminilidade convencional como demonstra a imagem da capa da revista francesa La Vie feminine (fig. 13). Na imagem, enfrentam-se a pequena chapeleira (emprego tipicamente feminino) e a agigantada figura de uma trabalhadora (DUBY; PERROT, 1991). As chapeleiras podem evocar retorno ao passado, uma postura delicada, um modo de vida elegante e sofisticado.

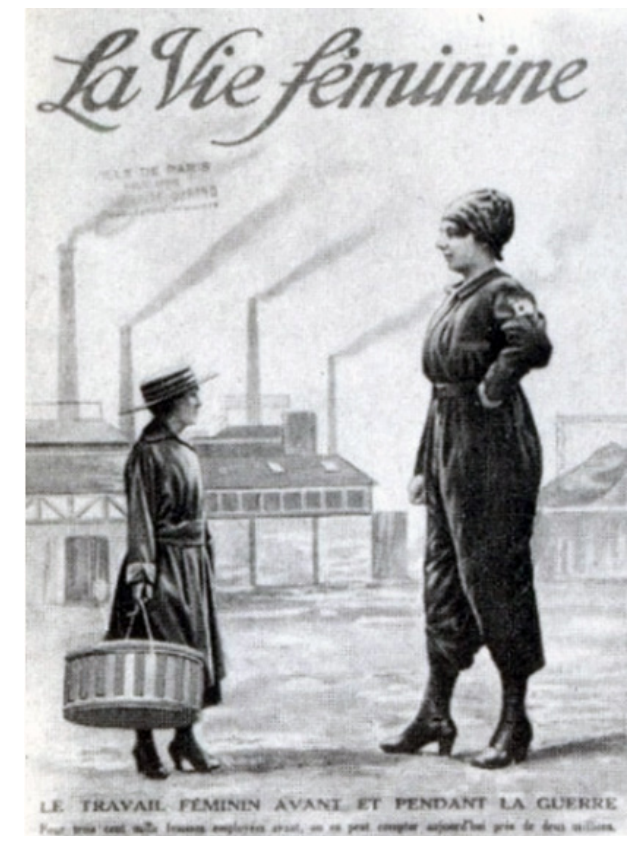

Figura 13- Capa da revista La Vie feminine, no 60, 15 de Abril de 1917 Fonte: Duby e Perrot (1991).

A campanha publicitária de $\mathrm{CH}$ (fig. 9) também traz referências sobre a usuária imaginada: uma mulher jovem e bonita. Ela usa coque e vestido, que podem sugerir elegância, já o corpete, aliado à postura corporal da jovem, parece evocar uma ideia mais sensual.

A jovem moça encontra-se em um ambiente íntimo, onde a aparição de uma penteadeira parece indicar que ela se encontra em um quarto. $O$ ambiente é requintado, apresentando uma decoração luxuosa a partir de artefatos brancos com detalhes em dourado, móveis estilo Império e estampas com o padrão $\mathrm{CH}$ que se distribuem pelas almofadas, papéis de parede e cúpula do abajur, personalizando o recinto. O cenário parece evocar algo sofisticado, tradicional, familiar e delicado.

De modo geral, a configuração da embalagem e as demais mídias parecem indicar que o fragrante $\mathrm{CH}$ Carolina Herrera destina-se a mulheres sofisticadas e abastadas, que prezam pelos valores tradicionais e familiares. Uma mulher jovem, sensual e descontraída, uma moça bem-educada que sabe de cor as regras de etiqueta. Uma mulher que não se tornou rica ou independente por esforço próprio, mas devido às heranças dos seus familiares. A usuária imaginada parece ser uma mulher que dá grande importância aos objetos de luxo, que conferem a ela momentos de prazer, distração e diversão.

\section{CH MEN}

A grife Carolina Herrera também produz coleções masculinas, que costumam trazer peças sóbrias e elegantes com cortes tradicionais, mas com toques modernos e urbanos

Projética Revista Científica de Design I Universidade Estadual de Londrina I V.2 I N.2 I Dezembro 2011 
Moda, Cultura \& Frascos de Perfume

através do uso de estampas, jeans, detalhes coloridos e modelagem justa (fig. 14).

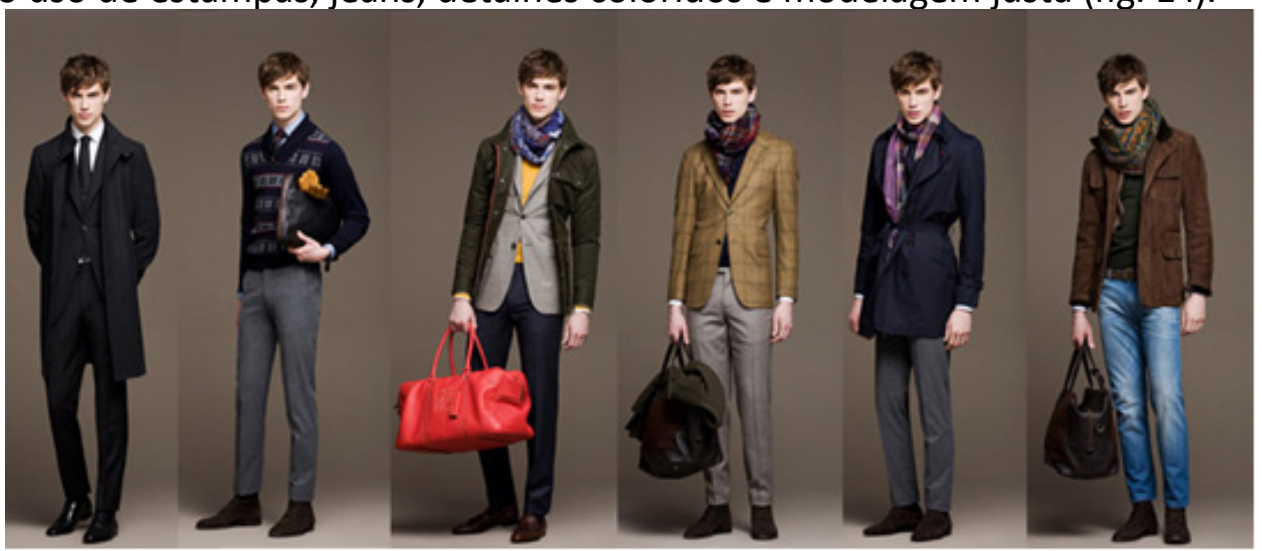

Figura 14- Coleção masculina do outono-inverno 2010 CH Carolina Herrera

Fonte: Carolina Herrera (2010)

O fragrante $\mathrm{CH}$ Men, lançado em 2009, também leva a assinatura de Carolina Jr., herdeira da grife (GUIA DE PERFUMES, 2010). A perfumista iniciou a criação em torno do verbo "viajar", procurando imprimir no fragrante a sua interpretação de viagem: a de olhar as coisas a partir de diferentes ângulos (CAROLINA HERRERA, 2010).

Para isso, a perfumista reuniu diferentes perspectivas sobre o mundo contando com a opinião de oito homens, que falaram sobre suas profissões, paixões e memórias de viagens. Estes foram escolhidos por compartilharem os valores do $\mathrm{CH}$ Man idealizado por ela: um homem sofisticado, aventureiro, charmoso e engraçado; um excelente profissional; alguém motivado a explorar a vida, percorrendo as ruelas das cidades grandes em busca de livrarias antigas e pequenos cafés.

O corpo da embalagem $\mathrm{CH}$ Men é um prisma de vidro de base retangular com os cantos levemente arredondados (fig. 15). Sua construção simétrica pode evocar estabilidade e suas formas retilíneas, solidez, força, racionalidade, seriedade e determinação.

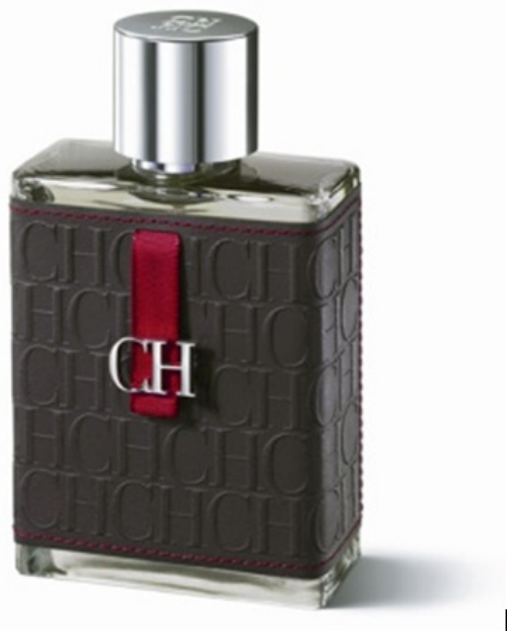

Figura 15- Imagem do frasco do perfume $\mathrm{CH}$ Men Fonte: Carolina Herrera (2010)

A tampa do frasco $\mathrm{CH}$ Men é idêntica à da embalagem da versão feminina $\mathrm{CH}$ : cilíndrica, com acabamento metálico e com as iniciais " $\mathrm{C}$ " e " $\mathrm{H}$ " em baixo relevo (fig. 16). A frente e grande parte das laterais do envoltório são recobertas por um couro marrom de tom escuro 
pespontado nas margens com uma linha vermelha (fig. 17).

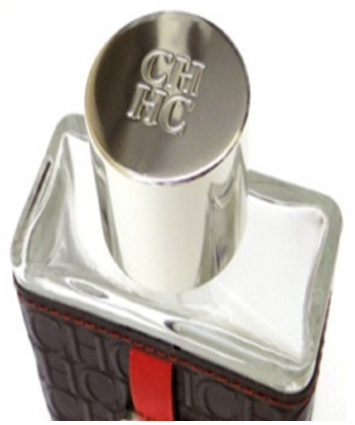

Figura 16- Tampa e cantos arredondados - frasco $\mathrm{CH}$ Men

Fonte: Elaborado pela autora
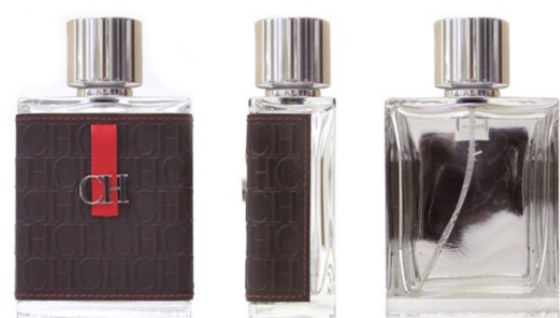

Figura 17- Vista frontal, lateral e posterior

Fonte: Elaborado pela autora

O couro marrom traz uma padronagem idêntica ao do couro vermelho do frasco $\mathrm{CH}$. A padronagem apresenta uma estrutura regular construída matematicamente, podendo manifestar ideia de organização, formalidade, tradição e estilo.

O uso do couro, um material de alto custo, pode fazer alusão aos produtos direcionados às classes mais abastadas, podendo significar luxo e riqueza. $O$ couro também pode remeter às atividades de caça e montaria - atividades provedoras e protetoras, praticadas como esporte pela elite (CARVALHO, 2008).

O tom castanho do material pode expressar ainda ideias de seriedade, utilidade, elegância e de algo antigo, fazendo lembrar a terra e a natureza (GUIMARÃES, 2000; NEGRÃO; CAMARGO, 2008; PEDROSA, 2002).

Na parte superior do couro da frente da embalagem sai uma fita vermelha de gorgurão canelado. Na parte inferior da fita encontram-se as iniciais " $\mathrm{CH}$ " com tipografia serifada idêntica à da padronagem e à da tampa. As iniciais são feitas de metal e, junto com a fita vermelha, fazem lembrar as medalhas de honra do exército (fig. 18), que podem aludir ao universo masculino.

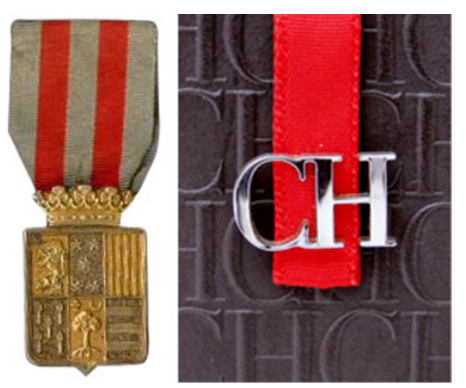

Figura 18- Medalha de honra do exército e acessório do frasco $\mathrm{CH}$ Men

Fonte: Carolina Herrera (2010) 
Moda, Cultura \& Frascos de Perfume

O formato, a cor, os acabamentos e os materiais da embalagem $\mathrm{CH}$, assim como os conceitos do perfume, acabam por evocar, segundo o site da grife, a inspiração do frasco $\mathrm{CH}$ Men: as malas antigas de viagem (fig. 19).

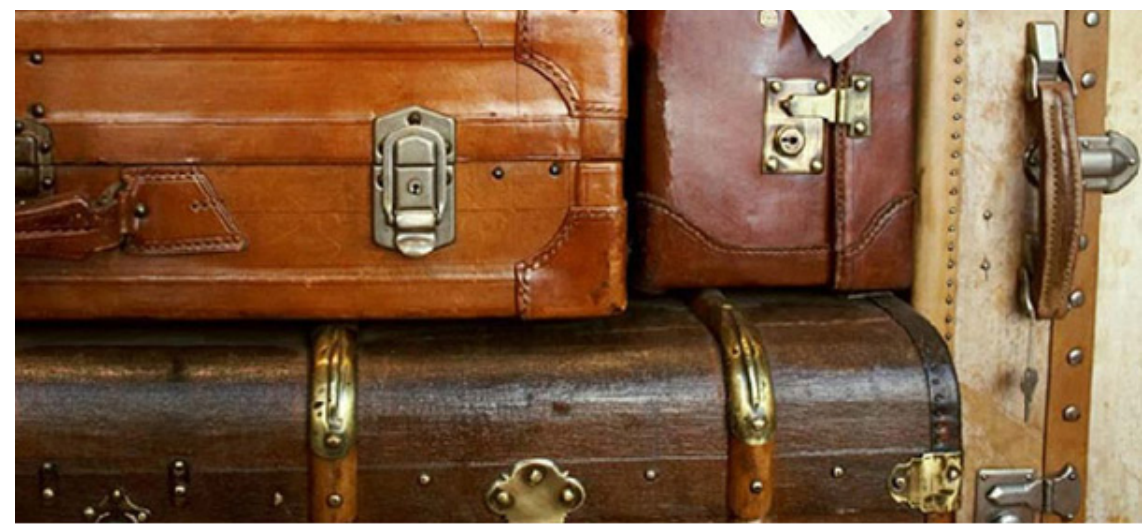

Figura 19- Inspiração CH Men

Fonte: Carolina Herrera (2010)

Os cantos arredondados e o castanho do couro do envoltório assemelham-se às cantoneiras e às cores das maletas. A tampa metálica faz lembrar os fechos das malas e o pespontado avermelhado - cor característica da grife - parece aludir ao seu acabamento artesanal.

O uso da mala antiga como referência parece trazer um apelo vintage ao produto, fazendo lembrar as décadas passadas, quando o uso de ternos pelos homens era mais usual que nos dias atuais, podendo remeter a ideias de elegância e sofisticação.

$\mathrm{O}$ nome do perfume $\mathrm{CH}$ Men refere-se a homens no plural, evocando a diversidade de experiências e pontos de vista dos oito profissionais que inspiraram o fragrante. Estes deram vida ao $\mathrm{CH}$ Man, que é composto não por uma, mas por diversas facetas de vários homens.

O CH Man imaginado (fig. 20) parece ser um homem viajado, culto, cheio de experiências que proporcionam a ele diferentes pontos de vista sobre o mundo. É um homem afortunado, bem sucedido, seguro, sofisticado e elegante. Alguém que valoriza e investe em produtos de alta qualidade e que parece praticar esportes associados às classes abastadas.

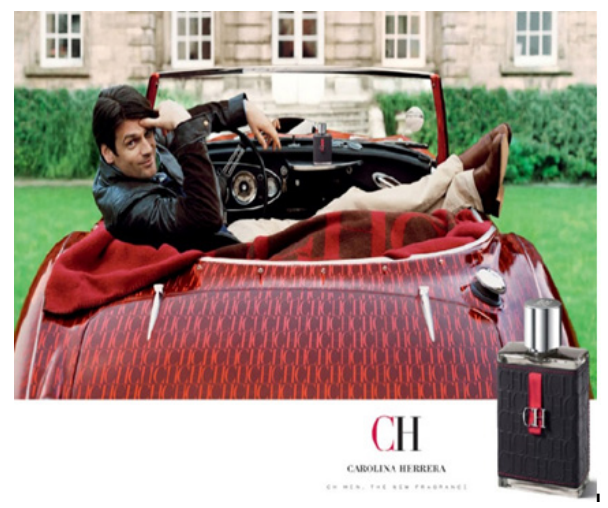

Figura 20- Propaganda de $\mathrm{CH}$ Men.

Fonte: em: <http://sephablog.com.br/wp-content/uploads/2010/02/ch_chmen1.jpg>. Acesso em: 01/12/2010.

A comparação entre as embalagens dos perfumes $\mathrm{CH}$ e $\mathrm{CH}$ Men dá margem ainda às diferenciações de gênero, prescrevendo características físicas e comportamentos aceitáveis para homens e mulheres. 
$\mathrm{O}$ formato cilíndrico ou arredonando do envoltório $\mathrm{CH}$, por exemplo, costuma ser usado com maior frequência nos produtos femininos por remeter à delicadeza, emoção e sensibilidade - ideologias reconhecidas culturalmente como femininas.

Já o frasco de $\mathrm{CH}$ Men é retangular e utiliza formas retilíneas que podem expressar conceitos de razão, segurança e poder. Ideias, que culturalmente, costumam ser associadas ao universo masculino.

Além disso, a embalagem $\mathrm{CH}$ Men é mais alta do que a $\mathrm{CH}$ (fig. 21). O fato pode fazer menção à ideia de que os homens são fisicamente maiores e mais fortes do que as mulheres.
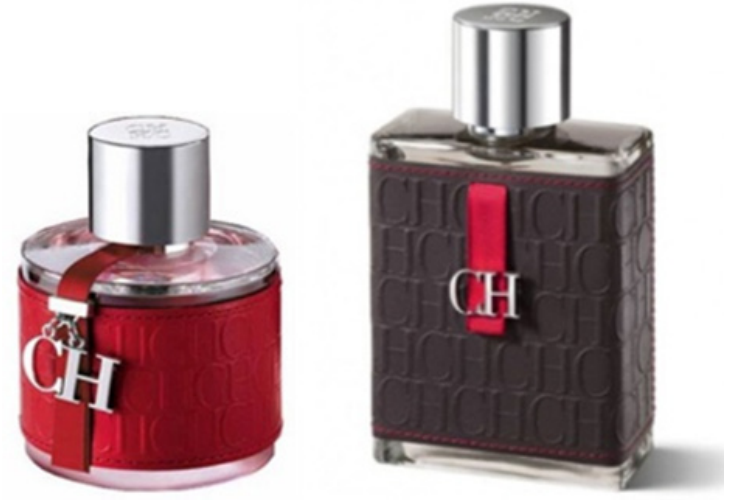

Figura 21- $\mathrm{CH}$ e $\mathrm{CH}$ Men

Fonte: Carolina Herrera (2010)

Os acessórios dos frascos também apresentam diferenciações de gênero. No envoltório feminino, as iniciais $\mathrm{CH}$ materializam-se em forma de pingente, um acessório utilizado comumente pelas mulheres. Já no frasco masculino, o acessório é configurado de modo a não lembrar um pingente, mas uma medalha de guerra, um símbolo viril, de força e poder.

As cores empregadas nos envoltórios trazem propostas diferentes. Enquanto o vermelho da embalagem feminina pode remeter à paixão, sedução, emoção, sensualidade e beleza, o marrom pode evocar utilidade, segurança, determinação e sobriedade. As cores, assim como os formatos, tamanhos e acessórios, reforçam os diferentes destinos dos perfumes: um voltado para o público masculino e outro para o feminino.

Apesar das diferenças de gênero, ambas as embalagens (e demais mídias dos perfumes) parecem construir a ideia de que os fragrantes $\mathrm{CH}$ e $\mathrm{CH}$ Men são direcionados para um público abastado que valoriza a aparência e produtos de alta qualidade e que gosta de sofisticação.

Este conjunto de práticas que os usuários imaginados abraçam parece estar de acordo com a imagem da grife e com o seu objetivo de criar produtos a partir de uma linguagem que evoque elegância.

\section{Considerações}

Os frascos de perfume do século XXI são exemplos da cultura material contemporânea; eles não apenas refletem a cultura, mas fazem parte dela, transmitem e reforçam determinados conceitos e valores.

Os aspectos simbólicos dos frascos de perfumes abrangem diversas categorias identitárias atualmente como gênero, classe e geração que influenciam o consumo dos fragrantes. A leitura das embalagens, pensadas a partir do conceito do usuário imaginado,

Projética Revista Científica de Design I Universidade Estadual de Londrina I V.2 I N.2 I Dezembro 2011 
Moda, Cultura \& Frascos de Perfume

dizem respeito ainda a perfis e estilos de vida.

Estes diversos pontos de apoio são bem recentes na história da perfumaria e parecem estar de acordo com a necessidade dos indivíduos externarem sua subjetividade.

A diversidade de embalagens e fragrantes procura atender não somente o público adulto, infantil, feminino, masculino, abastado ou menos favorecido, mas especialmente às necessidades de distinção individual das pessoas que compõe estas categorias.

E é através do consumo que as identidades, a ordem social e as relações sociais, constituídas pelos significados das coisas, são sustentadas, questionadas e reproduzidas.

As ideias sugeridas pelos frascos de perfume fazem parte das mudanças sócio-culturais e tecnológicas, sendo capazes de transformar as relações sociais e os modos de ver e consumir os fragrantes. Os designers criam imagens e significados para as embalagens que entram em contato com as sociedades, suas histórias e crenças, trazendo efeitos reais para os indivíduos.

Em cumplicidade com a moda, os frascos de perfume ganham novas dimensões na representação das relações sociais, traduzindo na materialidade de seus elementos os discursos sobre homens e mulheres, sobre tecnologia, sobre estilos de vida, sobre comportamentos. Estudar a configuração e a variedade dos frascos de perfume do início do século XXI é questionar as tradições e contradições que conjugam-se de forma nem sempre tão harmoniosa no projeto das embalagens.

\section{Referências}

ARTE em perfumes: mais do que o cheiro, o sucesso de uma nova fragrância pode depender do design da embalagem. Istoé, São Paulo, Edição, 1595, 26. abr. 2000.

ASHCAR, Renata. Brasilessência: a cultura do perfume. São Paulo: Nova Cultural, 2001.

ASHCAR, Renata. Entrevista concedida via-email. 10/02/2010.

BELLINO, Nina. Mensagem na garrafa. Revista Estilo, São Paulo, n. 76, p. 106-109. jan. 2009.

CAROLINA HERRERA. Disponível em: <http://www.carolinaherrera.com>. Acesso em: 22 nov. 2010.

CARVALHO, Vânia Carneiro de. Gênero e artefato: o sistema doméstico na perspectiva da cultura material - São Paulo, 1870-1920. São Paulo: Edusp, 2008.

CHANEL. A história do № 5. Disponível em: <http://www.chaneln5.com/pt-br/ ?x=0\&y=89\&wi $\mathrm{dth}=1259 \&$ height=654\#/world/the-story>. Acesso em: 21 mar. 2010.

CORNING MUSEUM OF GLASS. Perfume Bottles: From Design Table to Dressing Table. Disponível em: <http://www.cmog.org/dynamic.aspx?id=1278\& terms= dressing+table>. Acesso em: 21 maio 2010.

DUBY, Georges; PERROT, Michelle. História das mulheres no Ocidente: o século XX. Porto: Edições Afrontamento, 1991.

ESTÉE LAUDER. Fragance for women. Youth Dew. Disponível em: <http://www.esteelauder. $\mathrm{com} /$ products/620/Product-Catalog/Fragrance/For-Women/Youth-Dew/index.tmpl> . Acesso em: 23 mar. 2010. 
FRANÇA, Maureen Schaefer. Design \& Cultura: representações sociais nos frascos de perfume do início do século XXI. 2011. 251 f. Dissertação (Mestrado em Tecnologia) - Universidade Tecnológica Federal do Paraná. Curitiba, 2011.

Giddens, Anthony. Modernidade e Identidade. Rio de Janeiro, Jorge Zahar, 2002

GUIA de perfumes. São Paulo: L’Officiel, 2009.

GUIA de perfumes. São Paulo: L'Officiel, 2010.

GUIMARÃES, Luciano. A cor como informação: a construção biofísica, linguística e cultural da simbologia das cores. São Paulo: Annablume, 2000.

HALL, Stuart. A centralidade da cultura: notas sobre as revoluções culturais do nosso tempo. Educação \& Realidade, Porto Alegre, v. 22, n. 2, p. 15-46, jul./dez. 1997.

HALL, Stuart. Quem precisa de identidade? In: SILVA, Tomaz Tadeu da (Org.). Identidade e Diferença: a perspectiva dos estudos culturais. Petrópolis: Vozes, 2000.

JOLY, Martine. Introdução à análise da imagem. Campinas: Papirus, 1996.

KNIBIEHLER, Yvonne. Corpos e corações. In: DUBY, Georges; PERROT, Michelle. História das Mulheres: o século XIX. Porto: Afrontamento, 1991.

LARAIA, Roque de B. Cultura: um conceito antropológico. Rio de Janeiro: Jorge Zahar Editor, 2007.

MEDEIROS, Jusméri; QUELUZ, Gilson. Havaianas: um artefato cultural das identidades brasileiras no mundo globalizado. In: QUELUZ, Marilda Lopes (Org). Design \& Identidade. Curitiba: Ed. Peregrina, 2008.

MESTRINER, Fabio. Design de Embalagem: Curso Básico. São Paulo: Makron, 2002.

MILLER, Daniel. Stuff. Cambridge: Polity Press, 2009.

NEGRÃO, Celso; CAMARGO, Eleida Pereira. Design de embalagem: do marketing à produção. São Paulo: Novatec, 2008.

OLIVEIRA, Sandra R. Ramalho e. Imagem também se lê. São Paulo: Rosari, 2006.

ONO, Maristela Mitsuko. Design e cultura: sintonia essencial. Curitiba: Edição da autora, 2006.

ONO, Maristela Mitsuko. Design industrial e diversidade cultural: sintonia essencial. Estudos de casos nos setores automobilístico, moveleiro e de eletrodomésticos no Brasil. 2004. Tese (Doutorado em Arquitetura e Urbanismo) - Faculdade de Arquitetura e Urbanismo, Universidade de São Paulo, São Paulo, 2004.

PEDROSA, Israel. Da cor à cor inexistente. Rio de Janeiro: EDUFF, 2002. 
Moda, Cultura \& Frascos de Perfume

PERFUME 2000.com. The History of perfume. Disponível em: <http://www.perfume2000.com/ history/industrialrevolution.asp>. Acesso em: 27 dez. 2010.

PERFUMES: a história de um elemento vital na sedução. Revista Class. Disponível em: <http:// www.revistaclass.com.br/conteudo.asp?codConteudo=223>. Acesso em: 19 mar. 2010.

SANTOS, Marinês Ribeiro dos. Existe Design Brasileiro? Considerações Sobre o Conceito de Identidade Nacional. In: QUELUZ, Marilda Lopes (Org). Design \& Identidade. Curitiba: Ed. Peregrina, 2008.

SANTOS, Marinês Ribeiro dos. O design Pop no Brasil dos anos 1970: domesticidade e relações de gênero na Revista Casa \& Jardim. 2010. 294 f. Tese (Doutorado em Ciências Humanas) Universidade Federal de Santa Catarina. Florianópolis, 2010.

SEELING, Charlotte. Moda: o século dos estilistas - 1900-1999. Colônia: Könemann, 2000.

SEVCENKO, Nicolau. A Capital irradiante: técnica, ritmos e ritos do Rio. In: História da vida privada no Brasil. São Paulo: Cia da Letras, 1998.

SLATER, Don. Cultura do consumo e modernidade. São Paulo; Nobel, 2002.

SPARKE, Penny. An introduction to design and culture: 1900 to the present. London and New York: Routledge, 2004.

TANIA BO. Cartonagem. Disponível em:<http://www.taniabo.com/madmaria.htm>. Acesso em: 28 set. 2010.

WINNER, Langdom. Do artifacts have politics? In: MACKENZIE, Donald; WAJCMAN, Judy. The Social Shaping of Technology. Buckingham, Philadelphia: Open University Press, 1999.

WUCIUS, Wong. Princípios de forma e desenho. São Paulo: Martins Fontes, 1998. 